\title{
MONOGRAFIE/MONOGRAPH
}

Valérie Tothová, Věra Hellerová (eds) (2021). Využití měřicích nástrojů v ošetřovatelství [Use of measuring instruments in nursing]. Praha. NLN, s. r. o. 225 s. ISBN 978-80-7422-817-9. DOI: 10.32725/zsf.2021.74228179

\section{Bolest u dětí předškolního a mladšího školního věku}

kap. 7: DOI: 10.32725/zsf.2021.74228179.05

\section{Vèra Hellerová, Alena Machová, Andrea Schönbauerová}

University of South Bohemia in České Budějovice, Faculty of Health and Social Sciences, Institute of Nursing, Midwifery and Emergency Care, České Budějovice, Czech Republic

\section{Souhrn}

V současném pojetí léčebného a ošetřovatelského procesu hraje při léčbě a zvládání bolesti významnou úlohu multidisciplinární př́stup, kde nezastupitelnou roli hraje právě sestra. Sestra je nedílnou součástí týmu odborníků, jejichž cílem je dosažení uspokojivého terapeutického účinku při léčbě bolesti a s tím související zlepšení kvality života dětského pacienta.

Je potřeba, aby sestry přehodnotily své postoje k využívání hodnoticích systémů v neonatologii a pediatrii. Zavedení a používání hodnoticích systémů bolesti sice zvyšuje náročnost administrativní práce sester, ale pečlivé zaznamenávání projevů bolesti mohou nejen zvýšit efektivitu své práce, ale především zmírnit utrpení dětských pacientů (Fendrychová et al., 2001).

Absence posuzování bolesti u dětí vede $\mathrm{k}$ nedostatečnému poznání a neléčení bolesti. Vlastní hlášení bolesti u dětí jsou důležitá a měla by být vždy zvažována. Děti, které nejsou schopné verbální komunikace, nebo děti s kognitivním poškozením jsou zranitelnější kvưli tomu, že jejich bolest je podceňována (Palyzová, 2007a). Pro děti všech věkových a vývojových skupin jsou $\mathrm{k}$ dispozici spolehlivé nástroje pro hodnocení bolesti (Beltramini et al., 2017). Samotné měření intenzity bolesti (skóre bolesti) je pro hodnocení nedostatečné a nemělo by být používáno samostatně při rozhodování o léčbě bolesti. Měly by se používat spolehlivé nástroje k posouzení dopadu bolesti na kvalitu života dětí (spánek, aktivity sociální, školní atd.) a být vypracovány holistické plány zvládání bolesti. Hodnocení bolesti je zásadní pro účinné zvládání bolesti. Prvním krokem při hodnocení bolesti je záznam historie bolesti. Druhým krokem je posouzení bolesti dítěte pomocí vhodného nástroje pro hodnocení bolesti. Třetím krokem je vyhodnocení účinnosti intervencí zmírňujících bolest. Bolest by měla být pravidelně hodnocena, aby se zjistila př́tomnost bolesti a vyhodnocena účinnost léčby (Manworren a Stinson, 2016).

Klíčová slova: bolest u dětí, hodnocení bolesti, hodnoticí nástroj, účinnost léčby

\section{Podkapitoly:}

7.1 Faktory ovlivňující management bolesti

7.2 Symptomy bolesti u dětí

7.3 Hodnocení bolesti u dětí

7.4 Farmakologické tišení bolesti u dětí

7.5 Nefarmakologické tišení bolesti u dětí 
7.6 Ošetřovatelský proces u dítěte s bolestí

\section{Literatura}

1. Ambuel, B., et al. (1992). Assessing Distress in Pediatric Intensive Care Environments: The COMFORT Scale. J Pediatr Psychol 17(1): 95-109. DOI: 10.1093/jpepsy/17.1.95.

2. Aydin, D., Inal, S. (2019). Effect of breastfeeding and heel warming on pain levels during heel stick in neonates. Int J Nurs Pract 25(1): 12734. DOI: 10.1111/ijn.12734.

3. Baba, L. R., et al. (2010). The efficacy of mechanical vibration analgesia for relief of heel stick pain in neonates: a novel approach. J Perinat Neonatal Nurs 24(3): 274-283. DOI: 10.1097/JPN.0b013e3181ea7350.

4. Beltramini, A., et al. (2017). Pain Assessment in Newborns, Infants, and Children. Pediatr Ann 46(10): e387-e395. DOI: 10.3928/19382359-20170921-03.

5. Brand, K., Thorpe, B. (2016). Pain Assessment in children. Paediatr Anaesth 17(6): 270-273. DOI: 10.1016/j.mpaic.2016.03.007.

6. Calcaterra, V., et al. (2014). Music benefits on postoperative distress and pain in pediatric day care surgery. Pediatr Rep 6(3): 5534. DOI: 10.4081/pr.2014.5534.

7. Carter, B. (2013). Child and infant pain: prinicples of nursing care and management. Manchester: Springer-Science.

8. Claar, R. L., et al. (2008). Parental response to children's pain: The moderating impact of children's emotional distress on symptoms and disability. Pain 138(1): 172-179. DOI: 10.1016/j.pain.2007.12.005.

9. Cunningham, N. R., et al. (2016). Anxiety Adversely Impacts Response to Cognitive Behavioral Therapy in Children with Chronic Pain. J Pediatr 171: 227-233. DOI: 10.1016/j.jpeds.2016.01.018.

10. Dezfouli, S. M. M., Khosravi, S. (2020). Pain in child patients: A review on managements. Eur J Transl Myol 30(2): 8712. DOI: 10.4081/ejtm.2019.8712.

11. Fedora, M., a kol. (2012). Dětská anesteziologie. Brno: NCONZO.

12. Fendrychová, J. (2013). Hodnotící metodiky v neonatologii. Brno: NCONZO, $112 \mathrm{~s}$.

13. Fendrychová, J., et al. (2001). Hodnocení bolesti u novorozenců podle Bonnie Stevens-PIPP (Přehled za rok 2000). Pediatr Praxi 3: 137-139.

14. Forgeron, P. A., et al. (2010). Social functioning and peer relationships in children and adolescents with chronic pain: A systematic review. Pain Res Manag 15(1): 27-41. DOI: 10.1155/2010/820407.

15. Freund, D., Bolick, B. N. (2019). Assessing a Child's Pain. Am J Nurs 119(5): 34-41. DOI: 10.1097/01.NAJ.0000557888.65961.c6.

16. Gai, N., et al. (2020). A practical guide to acute pain management in children. J Anesth 34: 421-433. DOI: 10.1007/s00540-020-02767-x.

17. Grunau, R. V. E., Craig, K. D. (1987). Pain expression in neonates: Facial action and cry. Pain 28(3): 395410. DOI: 10.1016/0304-3959(87)90073-X.

18. Herdman, H., Kamitsuru, S. (Eds). (2016). Ošetřovatelské diagnózy. Definice a klasifikace 2015-2017. 10. vyd. Praha: Grada.

19. Hodgkinson, K., et al. (1994). Measuring pain in neonates: Evaluating an instru-ment and developing a common language. Aust J Adv Nurs 12(1): 17-22.

20. Chromá, J., Sikorová, L. (2013). Akutní bolest u dětí v ošetřovatelské diagnostice NANDA International. Kontakt 15(2): 158-164. DOI: 10.32725/kont.2013.019.

21. Kalousová, J. (2008). Bolest u dětí. In: Sedlářová, P., a kol. Základní ošetřovatelská péče v pediatrii. Praha: Grada, s. 118-126.

22. Kolektiv autorů (2006). Vše o léčbě bolesti: př́ručka pro sestry. Praha: Grada, $355 \mathrm{~s}$.

23. Krechel, S. W., Bildner, J. (1995). CRIES: a new neonatal postoperative pain measurement score. Initial testing of validity and reliability. Paediatr Anaesth 5(1): 53-61. DOI: 10.1111/j.1460-

9592.1995.tb00242.x. 
24. Kuttner, L. (2010). A Child in Pain: What Health Professionals Can Do to Help. USA Bethel: Crown Housle Publishing.

25. Lawrence, J., et al. (1993). The development of a tool to assess neonatal pain. Neonatal Netw 12(6): 5966.

26. Leng, H.-Y., et al. (2016). Combined non-pharmacological intervebtions ffor newborn pain relief in two degrees of pain procedures: A randomized clinical trial. Eur J Pain 20(1): 989-997. DOI: 10.1002/ejp.824.

27. Levy, N., et al. (2018). "Pain as the fifth vital sign" and dependence on the "numerical pain scale" is being abandoned in the US: Why? Br J Anaesth 120(3): 435-438. DOI: 10.1016/j.bja.2017.11.098.

28. Lyman, R. D., Hembree-Kigin, T. L. (2013). Mental Health Interventions with Preschool Children. Arizona: Springer-Science.

29. Lynch, M. (2001). Pain as the fifth vital sign. J Intraven Nurs 24(2): 85-94.

30. Macintyre, P., et al. (Eds). (2008). Clinical Pain Management: Acute Pain. London: CRC Press.

31. Machová, A., Brabcová, I. (2010). Úloha dětské sestry při laboratorním screeningu novorozenců. Pediatr Praxi 11(6): 398-399.

32. Malviya, S., et al. (2006). The revised FLACC Observational Pain Tool: Improved Reliability and Validity for Pain Assessment in Children with Cognitive Impairment. Pediatric Anesthesia 16(3): 258-265. DOI: 10.1111/j.1460-9592.2005.01773.x.

33. Manworren, R. C. B., Stinson, J. (2016). Seminars in Pediatric Neurology Pediatric Pain Measurement, Assessment and Evaluation. Semin Pediatr Neurol 23(3): 189-200. DOI: 10.1016/j.spen.2016.10.001.

34. Marečková, J. (2006). Ošetřovatelské diagnózy v NANDA doménách. Praha: Grada, 520 s.

35. Mathews, L. (2011). Pain in children: neglected, unaddressed and mismanaged. Indian J Palliat Care 17(Suppl.): S70-73. DOI: 10.4103/0973-1075.76247.

36. McGinnis, K., et al. (2016). Effect of Vibration on Pain Response to Heel Lance: A Pilot Randomized Control Trial. Adv Neonatal Care 16(6): 439-448. DOI: 10.1097/ANC.0000000000000315.

37. Merkel, S. I., et al. (1997). The FLACC: A Behavioural Scale for Scoring Postoperative Pain in Young Children, Pediatric Nurse 23(3): 293-297.

38. Oliveira, N. C. A. C., et al. (2017). Pain and distress outcomes in infants and children: a systematic review. Braz J Med Biol Res 50(7): e5984. DOI: 10.1590/1414-431X20175984.

39. Palermo, T. M., Eccleston, C. (2009). Parents of children and adolescents with chronic pain. Pain 146(12): 15-17. DOI: 10.1016/j.pain.2009.05.009.

40. Palermo, T. M., et al. (2014). Family and parent influences on pediatric chronic pain: a developmental perspective. Am Psychol 69(2): 142-152. DOI: 10.1037/a0035216.

41. Palyzová, D. (2007a). Dětská bolest. In: Lebl, J., Provazník, K., Hejcmanová, L., et al. Preklinická pediatrie. Praha: Galén, s. 209-212.

42. Palyzová, D. (2007b). Procedurální bolest v dětském věku. Bolest 4: 62 .

43. Paul, D., et al. (2015). Brunner \& Suddarth's Canadian Textbook of Medical-Surgical Nursing. Philadelphia: LWW.

44. Peters, J. W. B., et al. (2003). Neonatal Facial Coding System for assessing postoperative pain in infants: item reduction is valid and feasible. Clin J Pain 19(6): 353-363. DOI: 10.1097/00002508-20031100000003.

45. Reith, D. (2014). Managing pain in children age under 12 years. Best Practice Journal. [online] [cit. 202001-20]. Dostupné z: https://bpac.org.nz/BPJ/2014/March/pain.aspx

46. Řezníčková, A. (2008). Účinné strategie zvládání strachu a bolesti u dětí. In: Sedlářová, P., a kol. Základní ošetřovatelská péče v pediatrii. Praha: Grada, s. 127-130.

47. Sedlářová, P. (2008). Podávání léků dětem. In: Sedlářová, P., a kol. Základní ošetřovatelská péče v pediatrii. Praha: Grada, s. 118-126.

48. Sedlářová, P., a kol. (2008). Základní ošetřovatelská péče v pediatrii. Praha: Grada.

49. Sikorová, L. (2011). Potřeby dítěte v ošetřovatelském procesu. Praha: Grada, $208 \mathrm{~s}$.

50. Slamková, A., Poledníková, Ĺ. (2016). Ošetrovatel'ská diagnóza Chronická bolest' z pohladu pacienta. Kontakt 18(4): 254-260. DOI: 10.1016/j.kontakt.2016.09.002. 
51. Slater, R., et al. (2010). Oral cucrose as analgesic drug for procedural pain in newborns infants: a randomised controlled trial. Lancet 376(9748): 1225-1232. DOI: 10.1016/S0140-6736(10)61303-7.

52. Slover, R., et al. (2010). Chronic pediatric pain. Adv Pediatr 57(1): 141-162. DOI: 10.1016/j.yapd.2010.08.009.

53. Spence, K., et al. (2003). A Reliable Pain Assessment Tool for Clinical Assessment in the Neonatal Intensive Care Unit. J Obstet Gynecol Neonatal Nurs 34(1): 80-86. DOI: 10.1177/0884217504272810.

54. Tam, M. T., et al. (2020). Barriers and Facilitators to Effective Pain Management by Parents After Pediatric Outpatient Surgery. J Pediatr Health Care 34(6): 560-567. DOI: 10.1016/j.pedhc.2020.06.008.

55. Tóthová, V., a kol. (2014). Ošetřovatelský proces a jeho realizace. 2., aktual. vyd. Praha: Triton, $226 \mathrm{~s}$.

56. Trigg, E., Mohammed, T. A. (Eds). (2010). Practices in Children's Nursing: Guidelines for Hospital and Community. London: Elsevier.

57. Twycross, A., et al. (2009). Managing Pain in Children: A Clinical Guide. Oxford: Blackwell Publishing. DOI: $10.1002 / 9781444322743$.

58. Walker, S. M. (2008). Pain in children: recent advances and ongoing challenges. Br J Anaesth 101(1): 101-110. DOI: 10.1093/bja/aen097.

59. WHO (2012). WHO guidelines on the pharmacological treatment of persisting pain in children with medical illnesses. Geneva.

60. Zacharová, E., Haluzíková, J. (2013). Bolest a její zvládání v ošetřovatelské péči. Interní Med 15(11-12): 372-374. 